\title{
Variability of stable sulfur isotopic ratios in Spartina alterniflora
}

\author{
Judith M. Stribling ${ }^{1, *}$, Jeffrey C. Cornwell ${ }^{2}$, Carolyn Currin ${ }^{3}$ \\ 'Department of Biological Sciences, Salisbury State University, 1101 Camden Avenue, Salisbury, Maryland 21801, USA \\ ${ }^{2}$ Horn Point Laboratory, Center for Environmental Science, University of Maryland System, PO Box 775, Cambridge, \\ Maryland 21613, USA \\ ${ }^{3}$ National Marine Fisheries Service, 101 Pivers Island Rd, Beaufort, North Carolina 28516, USA
}

\begin{abstract}
The sulfur stable isotopic composition of Spartina alterniflora in a low salinity tidal creek system was related to differences in porewater sulfur chemistry determined by salinity, hydrodynamics, and season. The extent of porewater sulfide accumulation, the reoxidation of sulfide minerals, and sulfate limitation of sulfate reduction were important processes controlling the $\delta^{34} \mathrm{~S}$ of the sulfur available for plant uptake. The influence of sedimentary sulfate reduction rates on $S$. alterniflora $\delta^{34} S$ was demonstrated in the comparison of 2 sites with sımilar sulfate supply but differing hydrology; plant $\delta^{34} \mathrm{~S}$ values were heavier where sediments were more oxidized relative to plant $\delta^{34} \mathrm{~S}$ values from a frequently flooded marsh with more reduced sediments. The role of sulfate supply in determining $S$. alterniflora $8^{34} \mathrm{~S}$ values was apparent in the comparison of 3 sites with similar hydrology but differing salinity; shoot $\delta^{34} \mathrm{~S}$ decreased with increasing salinity. In low salinity marshes, oxidation of stored sulfide minerals in winter and spring led to lighter shoot $\delta^{34} \mathrm{~S}$ values, while sulfate depletion in late summer was associated with isotopically heavier shoot sulfur. Variability on spatial and temporal scales in sulfur stable isotopic composition of S. alterniflora has implications for the use of its $\delta^{34} \mathrm{~S}$ values in studies of trophic dynamics in estuarine marshes. The sulfur chemistry of the marsh sediments and the sampling season may both influence the stable isotopic signature of this important primary producer.
\end{abstract}

KEY WORDS: Spartina alterniflora S Sulfur - Stable isotopes - Oligohaline marshes

\section{INTRODUCTION}

Studies of trophic dynamics in estuaries have been enhanced by the use of stable isotopes of carbon and sulfur (Peterson et al. 1985, Peterson \& Howarth 1987. Sullivan \& Moncreiff 1990). Characteristic differences among the stable isotopic signatures of the major primary producers arise from isotopic differences in the carbon or sulfur sources of the plants, or from differences in isotopic fractionation during uptake. Estuarine primary producers vary in sulfur stable isotopic composition because salt marsh macrophytes derive much of their sulfur nutrition, at least indirectly, from isotopically light hydrogen sulfide produced via microbial sulfate reduction, whereas phytoplankton use isotopically heavier seawater sulfate.

-E-mail: jmstribling@ssu.edu
Implicit in this methodology is the assumption that the isotopic composition of each of the primary producers is relatively constant, both among different groups of live individuals and between live and detrital forms of the same plant (Stephenson et al. 1984). Recent studies have shown this assumption to be questionable for carbon (Fry \& Sherr 1984, Stephenson et al. 1984, Zieman 1986, Goering et al. 1990, Benner et al. 1991. Simenstad et al. 1993, Zohary et al. 1994). The stable isotopic composition of sulfur in primary producers is variable as well. In a short Spartina alterniflora marsh in Massachusetts (USA), live, dead and senescent plant $\delta^{34} \mathrm{~S}$ values ranged from -9.5 to +5.5 (Peterson et al. 1986); differences of about $14 \%$ have been found between live and standing dead $S$. alterniflora leaves (Currin et al. 1995). The $\delta^{34} \mathrm{~S}$ of live $S$. alterniflora in a Maryland creek encompassed a range of $12.2 \%$ (Stribling \& Cornwell 1997). Understanding the causes of 
this variability is critical to the effective use of multiple stable isotopes in studies of trophic dynamics.

Plants isotopically resemble the source of sulfur incorporated by their roots (Chukhrov et al. 1980); isotopic fractionation during the assimilation of sulfur is only about $+1.5 \%$ (Trust \& Fry 1992). Sulfur available for uptake by Spartina alterniflora usually includes both sulfate and sulfide. The relative importance of each to the plant has not been clearly established, although sulfide appears to be taken up preferentially (Carlson \& Forrest 1982). S. alterniflora is usually depleted in ${ }^{34} \mathrm{~S}$ relative to seawater sulfate, and it probably derives much of its sulfur from sulfide, when it is available, or from sulfate oxidized from sulfide in the root zone (Fry et al, 1982). The sulfur stable isotopic values and the relative abundance of sulfate and sulfide in marsh porewater can vary considerably, both spatially and temporally.

Bacterial sulfate reduction in marsh sediments discriminates against the heavier ${ }^{34} \mathrm{~S}$ isotope, with a fractionation of as much as $70 \%$ in the product hydrogen sulfide (Goldhaber \& Kaplan 1980). Rates of sulfate reduction increase with increasing organic matter and with waterlogging. In very reducing sediments, abundant sulfide results in more isotopically light sulfur available to Spartina alterniflora. On the other hand, in well-drained, elevated marsh soils with deeper oxygen penetration and low rates of sulfate reduction, the $\delta^{34} \mathrm{~S}$ of inorganic porewater sulfur should more closely resemble that of surface waters.

Salinity may also influence the $\delta^{34} \mathrm{~S}$ of marsh porewater, as sulfate concentrations below $4 \mathrm{mmol} \mathrm{l}^{-1}$ have been shown to reduce sulfate reduction rates in marine sediments (Goldhaber \& Kaplan 1980). Low salinity marshes with high organic inputs and poor drainage should be most likely to exhibit such sulfate limitation. Where sulfate is not readily replaced, fractionation cannot continue. The $\delta^{34} \mathrm{~S}$ of the sulfide pool begins to increase, eventually approaching that of the source tidal water sulfate (Chambers \& Trudinger 1979, Goldhaber \& Kaplan 1980, Peterson et al. 1986).

There may also be seasonal variability in the isotopic composition of porewater inorganic sulfur in temperate marshes. Sulfate reduction rates in U.S. Atlantic coastal marsh sediments reach a maximum in summer (cf. King 1988, Hines et al. 1989). In higher salinity marsh sediments, increasing sulfide concentrations from spring to late summer should result in a decrease in the $\delta^{34} \mathrm{~S}$ of the sulfur available to Spartina alterniflora (Carlson \& Forest 1982, Peterson et al. 1986). However, in lower salinity estuarine marshes, sulfate limitation may generate a different seasonal effect on $\delta^{34} \mathrm{~S}$ values. Tidal water sulfate availability may be greatly reduced in spring, and sulfate resupply to reducing sediments during summer may be limited as well.
The relationship between sediment sulfur chemistry and the sulfur isotopic composition of live Spartina alterniflora has not been thoroughly investigated. There is the potential for considerable variability in the $\delta^{34} \mathrm{~S}$ of this primary producer due to differences in the isotopic composition of dissolved inorganic sulfur determined by hydrodynamics and salinity. There may also be substantial seasonal variability.

The objective of this study was to determine the relationship between porewater sulfur cycling and the $\delta^{34} \mathrm{~S}$ values of live shoots of Spartina alterniflora. The work was conducted in a tidal creek and embayment that encompassed differing hydrological regimes and a range of salinities. The features investigated related to the supply and the demand for sulfate. These included salinity, sediment texture and organic content, porewater sulfide concentration, and sulfate:chloride ratios in porewater as an index of sulfate depletion. $S$. alterniflora was a dominant species throughout the salinity gradient, permitting the study of factors influencing its sulfur stable isotopic composition within a relatively small system. It is important to understand the effects of these variables on the $\delta^{34} \mathrm{~S}$ of $S$. alterniflora if we are to successfully use multiple stable isotopic composition in studies of trophic dynamics in temperate estuaries.

\section{METHODS}

Study site. The study was conducted in Monie Bay, an embayment on the Wicomico River on the lower Maryland eastern shore of Chesapeake Bay (USA). We sampled 4 marsh sites, with limited additional sampling at a fifth (Fig. 1); 4 sites are on Monie Creek, the largest creek feeding Monie Bay, and 1 site is in Monie Bay itself. The first site, designated ' $H W Y$ ', is at the uppermost navigable portion of Monie Creek, which is dammed above the site by a highway culvert. This point in the creek has the lowest salinity ( 0 to $4 \mathrm{ppt}$ ), and low elevation; the marsh is regularly flooded. The second sampling location ('DB') has intermediate salinity (2 to $12 \mathrm{ppt}$ ). We sampled 2 marsh sites at this location, a well-drained creek bank levee (DB1), which is irregularly flooded, and the low interior marsh behind it (DB2), which is regularly flooded. The fourth site ('DQ'), is at the southwestern end of Monie Bay, at Dames Quarter. Salinity at this site ranges from 4 to 18 ppt. The marsh is regularly flooded and is in a high energy environment. The final site, that of limited sampling ('BAY'), is near the mouth of Monie Creek; its salinity is similar to that at DQ. A detailed evaluation of sediment characteristics within the Monie Bay system was conducted by Kearney et al. (1994). 
Sampling and analytical methods. Plant material: Spartina alterniflora samples were collected in February, May, and September 1992 at each of the above sites, with the exception of the BAY site, which was sampled in August 1991. We sampled only live (green) shoots growing in areas of similar density. Plant height at peak biomass was similar for all 4 sites, ranging from 90 to $130 \mathrm{~cm}$. For each sample, 18 pooled shoots were washed free of debris, rinsed in deionized water, dried at $65^{\circ} \mathrm{C}$ to constant weight and ground in a Wiley Mill (1 mm mesh). We did not leach plant material after grinding as is sometimes done to remove free sulfate (not assimilated by higher consumers). Carlson \& Forrest (1982) found little difference between the $\delta^{34} \mathrm{~S}$ values of free sulfate and total or residual sulfur in $S$. alterniflora; free sulfate in the plant also appeared to be derived from porewater sulfide.

Soil: Soil from each marsh sampling location was collected during the growing season for determination of texture (pipette method, Folk 1974) and of loss on ignition (LOI) as an index of organic matter content. For LOI, dried samples were ashed for $6 \mathrm{~h}$ at $500^{\circ} \mathrm{C}$

Porewater: We measured porewater dissolved sulfide and sulfate and surface water sulfate concentrations monthly from January to November No porewater sampling was conducted at the BAY site. All water samples were filtered through Whatman GF/F filters. Porewater samples were collected using modified Hesslein (1976) equilibrators. The equilibrators were of plexiglass, $30 \mathrm{~cm}$ long, with 5 round chambers of $4 \mathrm{~cm}$ diameter and $12 \mathrm{ml}$ volume. Porewater sampling was thus integrated from five $4 \mathrm{~cm}$ deep sections centered at depths of $3,8,13,18$ and $23 \mathrm{~cm}$. These depths encompassed the root zone of Spartina alterniflora, which was concentrated between approximately 5 and $15 \mathrm{~cm}$. Each equilibrator was initially filled with deoxygenated deionized water adjusted to the approximate salinity of the sampling site with $\mathrm{NaCl}$. The holes were covered with $0.2 \mu \mathrm{m}$ polycarbonate membrane and with $120 \mu \mathrm{m}$ Nytex mesh to protect the membrane. The equilibrators were submerged overnight in deoxygenated water that was bubbled with $N_{2}$, then deployed for 10 to $14 \mathrm{~d}$.

For dissolved free sulfide determination, we sampled water directly from the equilibrator chamber (Lambert \& Oviatt 1986) through a filter into diamine sulfide reagent (Cline 1969) for colorimetric analysis. The remainder of the sample was divided into aliquots and stored frozen for subsequent sulfate and chloride analysis, conducted using a Dionex ion chromatograph. The $\delta^{34} \mathrm{~S}$ of porewater sulfate was delermined for samples from the 3 higher salinity locations (DB1, DB2 and DQ) and from a subtidal creek bank near the DB2 marsh. For this analysis, May and August samples from pooled depths of 8 to $18 \mathrm{~cm}$ were frozen, thawed, and filtered to remove precipitated elemental sulfur formed by oxidation of sulfide. Although sulfide may chemically oxidize completely to sulfate, in other work on porewater from Chesapeake Bay sulfate-depleted deep sediments, with sulfide concentrations of 2 to 3 mmol $\mathrm{l}^{-1}$, no detectable sulfate was present after thawing and filtering (Cornwell unpubl.).

Surface water: Coincident with retrieval of the equilibrators, we collected duplicate samples from the
Fig. 1. Monie Bay and study sites, HWY, DB1, DB2, $B A Y$, and DQ, Maryland, USA

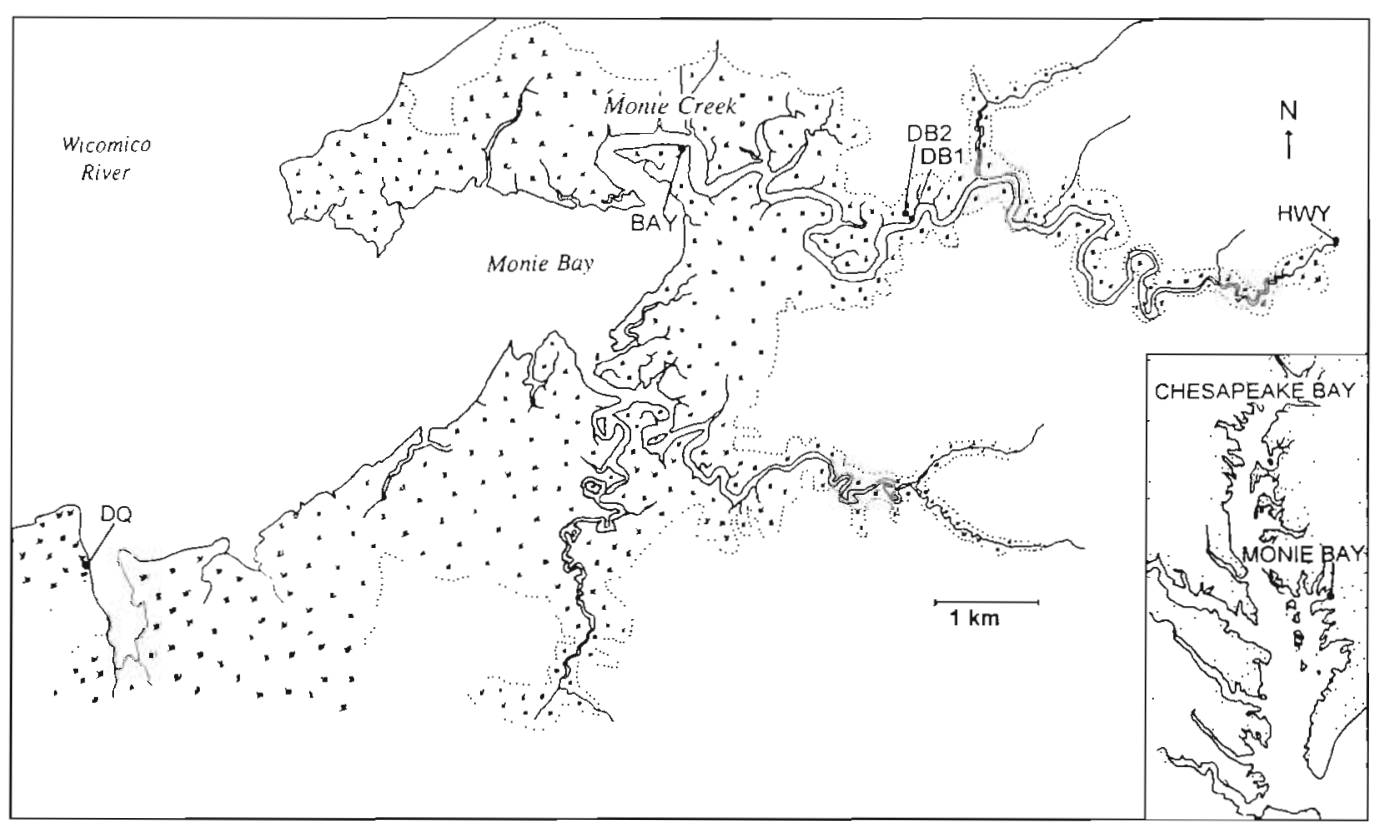




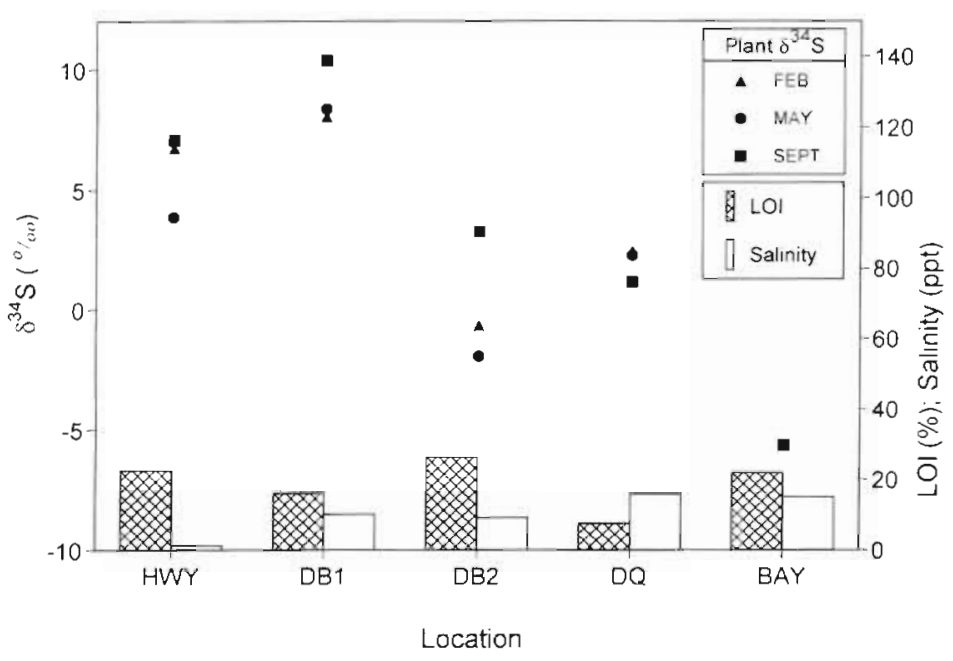

Fig. 2. $\delta^{34} \mathrm{~S}$ of Spartina alterniflora shoots by sampling site, with illustration of salinity and loss on ignition (LOI) for each site. The BAY site was sampled in August

surface water (approximately $5 \mathrm{~cm}$ depth) adjacent to each marsh site (except the BAY site) for sulfate and chloride determination. We also determined the $\delta^{34} \mathrm{~S}$ of sulfate in surface water samples from the HWY, DB and BAY sites in August. Sulfate in porewater and in surface water was precipitated as $\mathrm{BaSO}_{4}$ (Hall et al. 1988).

Stable isotopic analysis: Analysis of the stable sulfur isotopic composition of plant material and of $\mathrm{BaSO}_{4}$ samples was performed at Coastal Science Laboratories, Austin, Texas, USA; accuracy was within $0.5 \%$. Sulfur isotopic data are expressed in conventional $\delta$ notation, relative to Canyon Diablo troilite.

\section{RESULTS}

\section{Spartina alterniflora $\delta^{34} \mathrm{~S}$}

The $\delta^{34} \mathrm{~S}$ of Spartina alterniflora in the 5 study sites ranged from +10.4 to $-5.6 \%$ (Fig. 2). The heaviest isotopic compositions of $S$, alterniflora were found at the DB1 site (mean $8.9 \%$ ), and the lightest at BAY (-5.6\%). Treating sampling dates as replicates, the variability in $\delta^{34} \mathrm{~S}$ values among the first 4 sites was strongly associated with location ( $\mathrm{p}=0.02$, KruskalWallis non-parametric ANOVA; Wilkinson 1990).

The $\delta^{34} \mathrm{~S}$ values for samples collected within each site were relatively similar; however, there also appeared to be sea- sonal variability within sampling locations. With the exception of plants from the DQ site, the heaviest Spartina alterniflora $\delta^{34} \mathrm{~S}$ values occurred in September, and the lightest values generally occurred in May, with as much as a $5.2 \%$ difference between the 2 sampling dates. At the DQ site, there may have been a slight decrease in $\delta^{34} \mathrm{~S}$ over the growing season.

\section{Salinity and sulfate supply}

Porewater sulfate and chloride concentrations illustrated the effect of the salinity gradient on the supply of sulfate. At the upstream HWY site, porewater sulfate concentrations were below $1.5 \mathrm{mmol} \mathrm{l}^{-1}$ in all months except July, whereas they averaged above $8 \mathrm{mmol} \mathrm{l}^{-1}$ for all months of the year at DQ. Values were intermediate at the $2 \mathrm{DB}$ sites (Fig. 3).

Mean annual chloride concentrations in porewater (Fig. 4) represented salinities ranging from a high of 15.7 ppt at DQ to a low of 1.3 ppt at HWY. The mean salinities of the DB sites were similar at 10.1 and $9.2 \mathrm{ppt}$ at $D B 1$ and $D B 2$, respectively. Seasonal variability was marked at the 3 lower salinity locations; the lowest porewater chloride concentrations were present in March and the highest concentrations were present in July at all 3 sites. On the other hand, porewater salinity was relatively constant throughout the year at $D Q$, the site in closest proximity to Chesapeake Bay (Fig. 4). 


\section{Sediments}

Based on LOI values, the BAY site was relatively high in organic matter, and it had the finest-textured sediments of any of the locations studied (Table 1). The $D Q$ site represented the opposite extreme in both features. The HWY and DB2 sediments most closely resembled BAY in texture and organic content, whereas DB1, though fine textured, had lower soil organic content (Table 1).

\section{Porewater indices of sulfate demand}

The sampling sites differed markedly in sulfate depletion (based on sulfate: chloride ratios) and in sulfide concentration of porewater. Mean sulfate:chloride ratios for May to August were lowest at HWY and DB2 in sub-surface sediments (Table 1). Both sites showed very rapid sulfate depletion early in the season (Fig. 5). The DB1 and DQ sites had similar, higher sulfate:chloride ratios during the growing season. Periods of extensive sulfate depletion were exhibited at all 3 lower salinity sites, whereas at DQ, the sulfate:chloride ratios dropped substantially only during July (Fig. 5).

Porewater concentrations of dissolved sulfide at the HWY site never exceeded $500 \mu_{\mathrm{mol} \mathrm{l}}^{-1}$, and levels were extremely low at the DB1 site as well, with concentrations below $100 \mu \mathrm{mol} \mathrm{l}^{-1}$ in all months except September (Fig. 6, Table 1). On the other hand, porewater sulfide concentrations at DB2 exceeded $1000 \mu \mathrm{mol} \mathrm{l}^{-1}$ almost throughout the growing season, and they averaged near $1500 \mu \mathrm{mol} \mathrm{l^{-1 }}$ from May to September in sub-surface sediments (Fig. 6).

Table 1. Sediment characteristics at 5 locations in Monie Bay, $M D, U S A$. The $\delta^{34} S$ values ( $\%$ ) for solid phase inorganic sulfur ( 8 to $10 \mathrm{~cm}$ depth) are from Cornwell et al. (1990) and from Kearney et al. (1994). Values for porewater chloride (mmol $\left.\mathrm{L}^{-1}\right)$, sulfide $\left(\mu \mathrm{mol} \mathrm{l}^{-1}\right)$, and sulfate:chloride are means for the months from May to August, for depths below $3 \mathrm{~cm}$. LOI: loss on ignition $(\%)$; S/S/C: sand/silt/clay $(\%)$

\begin{tabular}{|c|c|c|c|c|c|c|}
\hline \multirow[t]{2}{*}{ Site } & \multicolumn{3}{|c|}{ Solid phase } & \multicolumn{3}{|c|}{ Porewater } \\
\hline & LOI & $\mathrm{S} / \mathrm{S} / \mathrm{C}$ & $\delta^{34} S$ & {$\left[\mathrm{Cl}^{-}\right]$} & {$\left[S^{2-}\right]$} & $\mathrm{SO}_{4}{ }^{2-}: \mathrm{Cl}^{-}$ \\
\hline HWY & 22.6 & $1 / 59 / 40$ & 2.4 & 34 & 105.3 & 0.010 \\
\hline DB1 & 16.1 & $0 / 59 / 41$ & -2.5 & 176 & 21.5 & 0.029 \\
\hline DB2 & 26.4 & $0 / 55 / 45$ & -11.1 & 169 & 1338.5 & 0.013 \\
\hline$D Q$ & 7.6 & $76 / 7 / 17$ & & 215 & 127.3 & 0.034 \\
\hline BAY & 22.0 & $1 / 34 / 65$ & -22.4 & & & \\
\hline
\end{tabular}

Both the HWY and DB2 sites exhibited relatively early onset of sulfide production, with the highest concentrations recorded in July. Conversely, sulfide levels at both DQ and DB1 did not peak until September, at about the time plant senescence began (Fig. 4).

\section{Sediment, surface water and porewater $\delta^{34} \mathrm{~S}$}

The stable isotopic ratios of the solid phase inorganic sulfur of Monie Creek sediments derive from the conditions during deposition of iron sulfide minerals and thus provide a record of the sulfur stable isotopic composition of sulfide produced at each site. These values decreased with increasing salinity, from a high of $+2.4 \%$ at the HWY site to $-22.8 \%$ at the BAY site marsh.

Values for surface water sulfate at the downstream BAY site were indistinguishable from the $\delta^{34} \mathrm{~S}$ of seawater $(+21.0 \%)$, but they increased upstream, and the HWY site may have been slightly enriched in ${ }^{34} \mathrm{~S}$ relative to seawater (Table 2). There was a negative correlation with salinity in the sulfur stable isotopic composition of surface water and sediment inorganic sulfur at the HWY, DB2 and BAY sites (Fig. 7), 3 sites with similar hydrodynamic features, organic content, and sediment texture (Table 1).

The DB2 site exhibited the heaviest $\delta^{34} \mathrm{~S}$ porewater sulfate values in both May and August, and DB1 and $D Q$ the lowest. In August, the porewater sulfate $\delta^{34} \mathrm{~S}$ value was $10 \%$ higher at the DB2 site than at the more oxidized DB1 site. Values increased over the growing season; for the DB2 intertidal and subtidal sediments, August $\delta^{34} \mathrm{~S}$ values for porewater sulfate were 7 or $8 \%$ higher than those for May (Table 2). 


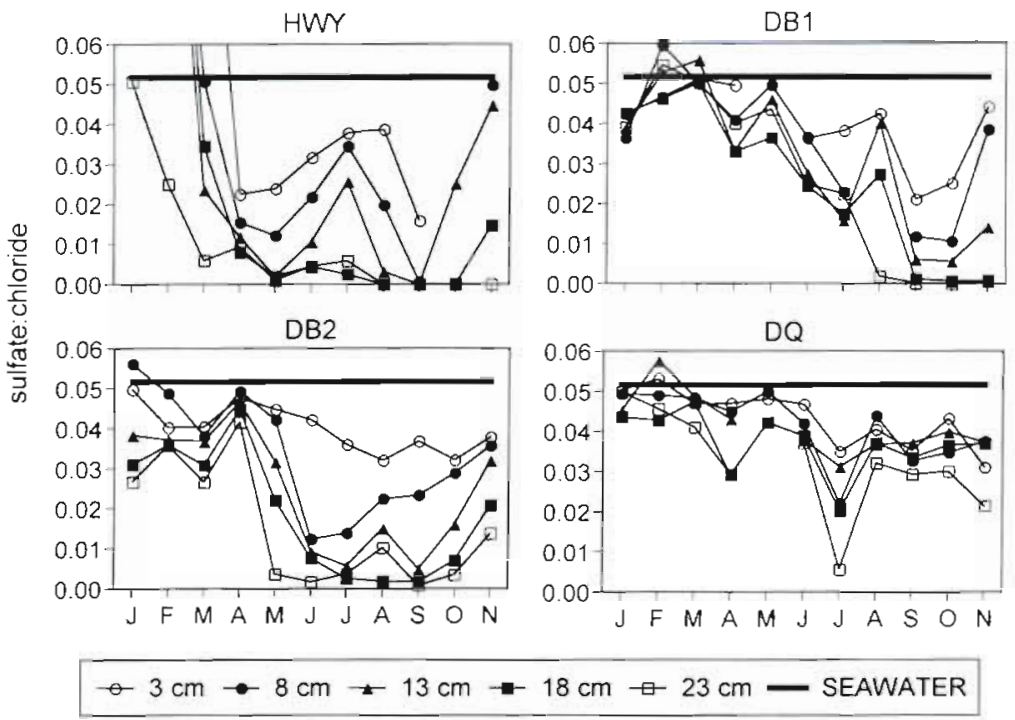

Fig. 5. Porewater sulfate:chloride molar ratios. Plant roots were concentrated at 8,13 , and $18 \mathrm{~cm}$ depth (solid symbols)

\section{DISCUSSION}

Hydrodynamic differences among sites were manifested in the organic content of the sediments and in porewater sulfide concentrations and degree of sulfate depletion. The influence of hydrodynamic flushing on these parameters is demonstrated in a comparison between 2 sites of similar salinity: the well-drained creekbank site DB1 and the low, frequently flooded DB2 marsh. The DB2 sediments were enriched in organic matter relative to DB1 sediments. The former had a much earlier onset and longer duration of sulfate depletion (Fig, 5) and far higher concentrations of porewater sulfide (Fig. 6).

Table 2. Sulfur stable isotopic composition (\%) of porewater and surface water sulfate. Duplicate samples were analyzed for surface water

\begin{tabular}{|llc|}
\hline & Site & $\delta^{34} \mathrm{~S}$ \\
\hline Porewater & & \\
May & DB1 & +21.5 \\
& DB2 & +24.4 \\
& DB subtidal & +22.9 \\
August & DQ & +21.1 \\
& DB1 & +22.2 \\
& DB2 & +32.2 \\
Surface water & DB subtidal & -30.2 \\
August & DQ & \\
& HWY & $+22.5_{i}+22.6$ \\
& DB & $+21.8_{i}+21.6$ \\
& BAY & $+21.0 ;+20.7$ \\
\hline
\end{tabular}

Differences in the $\delta^{34} \mathrm{~S}$ values of Spartina alterniflora collected from DB1 and DB2 (Fig. 2) can be related to the contrasting sediment processes at these sites. The lighter sulfur stable isotopic signatures of $S$. alterniflora at the DB2 site were associated with greater production of hydrogen sulfide, which is depleted in ${ }^{34} \mathrm{~S}$. The sulfur pool available to $S$. alterniflora at the DB1 site, on the other hand, was more readily replenished by advecting surface water, as evidenced by the porewater sulfate $\delta^{34} \mathrm{~S}$ values (Table 2), and by the minimal sulfide concentrations at this infrequently flooded site (Table 2). The difference of $8.7 \%$ between the mean $\delta^{34} \mathrm{~S}$ values for plants from these 2 sites indicates that hydrodynamic effects on porewater sulfur chemistry had a substantial influence on the $\delta^{34} S$ of $S$. alterniflora in this system. This pattern has also been observed in higher salinity marshes in North Carolina and Massachusetts. In North Carolina, S. alterniflora from sandy sediments in a transplanted marsh had $\delta^{34} \mathrm{~S}$ values ca $10 \%$ heavier than the $\delta^{34} \mathrm{~S}$ values from a natural marsh with finer sediment texture and higher organic content (Currin et al. 1995). In Massachusetts, short S. alterniflora $\delta^{34} \mathrm{~S}$ values from an interior marsh were lighter than the values for tall S. alterniflora along a creekbank (Peterson et al. 1986).

However, flooding regime and sediment geochemistry did not completely determine the sulfur isotopic composition of Spartina alterniflora in Monie Bay. The HWY, BAY and DB2 sites were comparable hydrodynamically, with low rates of flushing, fine-grained,

Table 3. Reported values for $\delta^{34} \mathrm{~S}$ (\%) of Spartina alterniflora shoots. Except where noted, \pm values are standard deviations With the exception of Deegan et al. (1990), Cornwell et al. (1990), Deegan \& Garritt (1997) and this study, all studies were conducted in high salinity (>20 ppt) marshes

\begin{tabular}{|lcl|}
\hline Location (USA) & $\delta^{34} \mathrm{~S}$ & Source \\
\hline Georgia & $0.9 \pm 5.2$ & Peterson \& Howarth (1987) \\
Louisiana & 5.6 & Deegan et al. (1990) \\
Maryland & $2.3 \pm 3.8$ & This study \\
Maryland & $1.6 \pm 5.2$ & Cornwell et al. (1990) \\
Massachusetts & & \\
Short form & $-3.6 \pm 5.0$ & Peterson et al. (1986) \\
Tall form & $-3.3 \pm 3.3$ & Peterson et al. (1986) \\
Massachusetts & $3.5 \pm 6.6$ & Deegan \& Garritt (1987) \\
Mississippi & $1.4 \pm 2.2$ (SE) & Sullivan \& Moncreiff (1990) \\
North Carolina & 0.0 & Carlson \& Forrest (1982) \\
North Carolina & -9.6 & Currin et al. (1995) \\
Texas & $4.5,3.5$ & Fry et al. (1982) \\
\hline
\end{tabular}




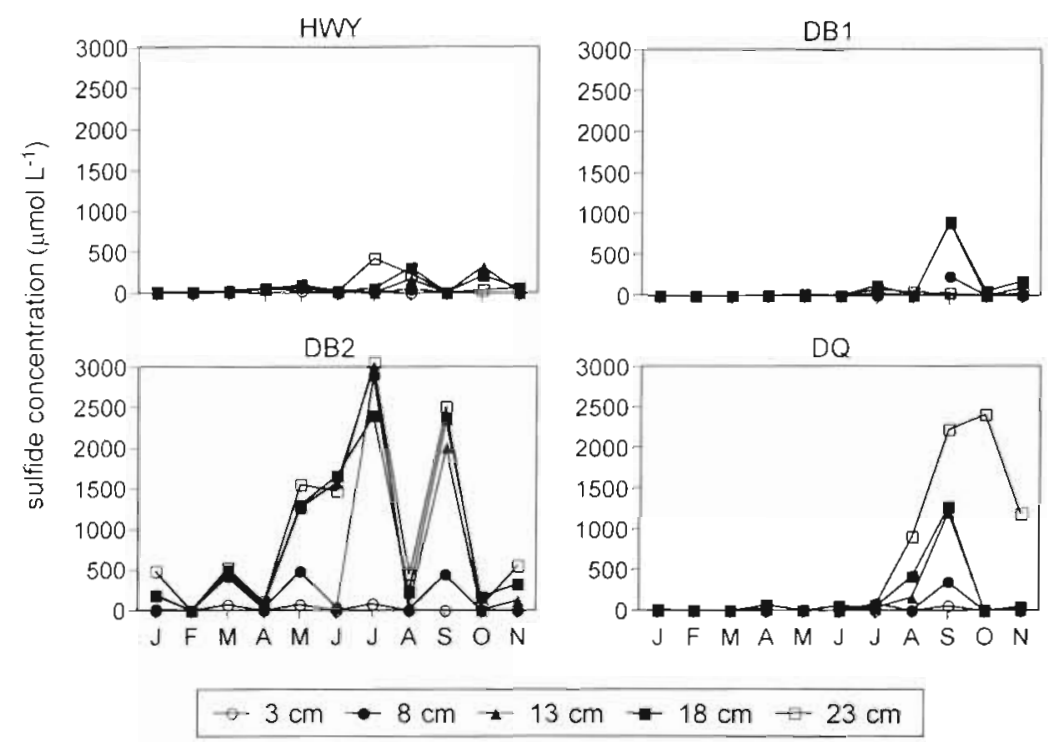

Fig. 6. Porewater sulfide concentrations. Plant roots were concentrated at 8,13 , and $18 \mathrm{~cm}$ depth (solid symbols)

organically rich sediments, and the potential for high rates of sulfate reduction. Nevertheless, the sulfur stable isotopic compositions of $S$. alterniflora from these locations differed considerably, ranging from -5.6 to $5.9 \%$. Furthermore, the DB1 and DQ sites both had relatively low organic contcnt, lower sulfide concentrations and sulfate depletion, and the potential for enhanced flushing, due either to infrequent flooding (DB1) or to very sandy texture (DQ). However, S. alterniflora from these 2 well-drained, more oxidized marshes had very different $\delta^{34} \mathrm{~S}$ values as well. Variation in the $\delta^{34} \mathrm{~S}$ values of $S$. alterniflora within these groups can be attributed to the differences in salinity regime.

In high salinity marshes where new sulfate is continually resupplied from surface water, the sulfide pool has a relatively light stable isotopic signature. However, under conditions of sulfate limitation in lower salinity systems, as the sulfate pool is depleted by sulfate reduction, porewater sulfide becomes progressively heavier isotopically. The $\delta^{34} \mathrm{~S}$ of Spartina alterniflora in low salinity marshes should therefore be heavier than that of plants growing in euhaline marshes of similar flood regime and sediment geochemistry. Among the heaviest $\delta^{34} \mathrm{~S}$ values for $S$. alterniflora reported in the literature are values of $5.6 \%$ (Deegan et al. 1990) and 8.2\%o (Deegan \& Garritt 1997), both from low salinity $(<15 \mathrm{ppt}$ ) marshes (Table 3$)$. The heavy $\delta^{34} \mathrm{~S}$ values $(\bar{x}=5.9 \%$ HWY,
8.9\% DB1) from upstream Monie Creek support this model. In addition, the $\delta^{34} \mathrm{~S}$ values of $S$. alterniflora in the hydrodynamically similar HWY, DB2 and BAY marshes decreased as salinity increased (Fig. 7). The $\delta^{34} \mathrm{~S}$ values at DB1 were heavier than those at the similarly well-drained but higher salinity $D Q$ site; the $\delta^{34} S$ values at $D Q$ most closely resembled those from other high salinity marshes.

The relatively enriched $\delta^{34} \mathrm{~S}$ values of Spartina alterniflora from the low salinity HWY site may result from uptake of isotopically enriched sulfide produced under conditions of sulfate depletion. In porewater at the HWY site, there was rapid sulfate depletion in spring and temporal variability in sulfate:chloride ratios (Fig. 5), suggesting that the supply of sulfate limited sulfate reduction (Howarth \& Teal 1979, Stribling 1994). A short-term increase in sulfate:chloride ratios in response to increasing salinity reflects very low rates of sulfate reduction and is characteristic of systems that are sulfate limited (Howarth \& Teal 1979). Such a response occurred at all sampling depths at the HWY site from. Tune to August (Fig. 5).

Salinity, as it determines porewater sulfate concentrations, may also influence the pattern of seasonal variability in the $\delta^{34} \mathrm{~S}$ of Spartina alterniflora. In high salinity (20 to $30 \mathrm{ppt}$ ) marshes in Massachusetts and

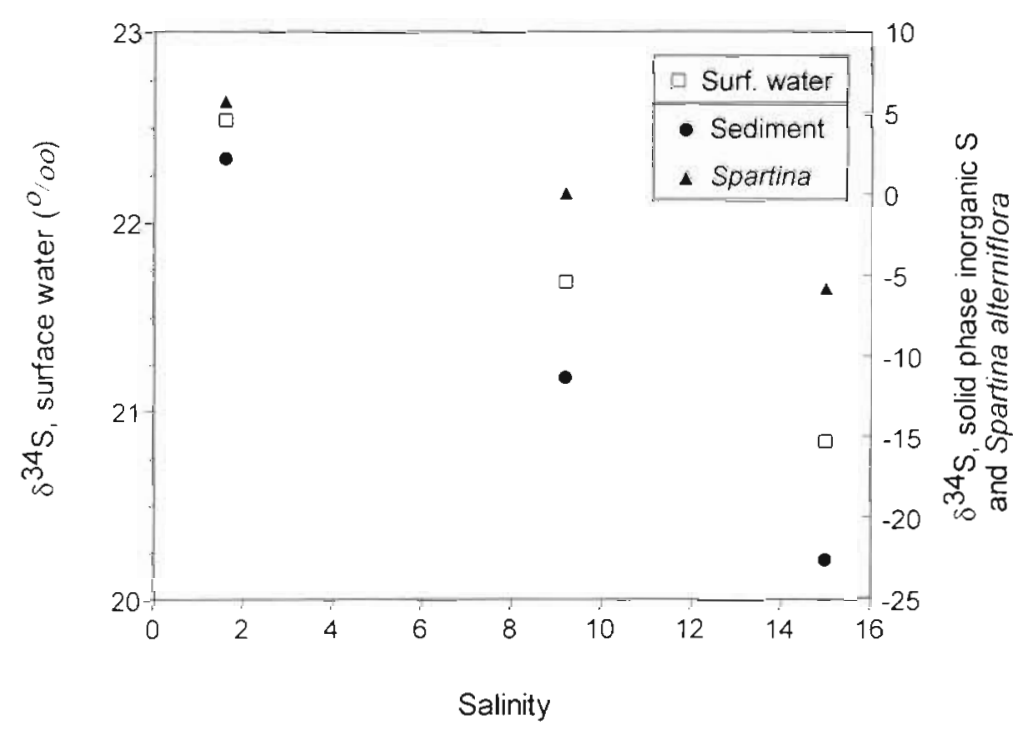

Fig. 7. Surface water sulfate, solid phase inorganic S, and Spartina alterniflora shoot $\delta^{34} \mathrm{~S}$ as a function of salinity. The 3 salinities plotted, for each function, represent mean annual salinity at the HWY, DB2 and BAY sites (from low to high) 
North Carolina, the $\delta^{34} \mathrm{~S}$ of $S$, alterniflora decreased over the growing season (Peterson et al. 1986 and Currin et al. 1995, respectively) as it did at the higher salinity $D Q$ site in this study. This is consistent with plant uptake of isotopically lighter sulfide accumulating with increasing sulfate reduction rates. However, this seasonal pattern may not occur at low salinities. The $S$. alterniflora $\delta^{34} \mathrm{~S}$ values at the HWY, DB1 and DB2 sites increased between May and September (Fig. 2). There are 2 possible explanations for the heavier September values at these sites, both involving sulfate limitation of sulfate reduction. If porewater sulfate became strongly depleted as the growing season progressed, as was the case at the 2 DB sites, the potential for fractionation via sulfate reduction would decrease and the sulfide taken up by the plant would become isotopically heavier. Alternatively, in very sulfate-limited marshes with low rates of sulfate reduction, so little sulfide is produced that much of the sulfur taken up by plants later in the growing season may be isotopically heavier tidal water sulfate.

The lighter $\delta^{34} \mathrm{~S}$ values for Spartina alterniflora in winter and spring at the HWY and the $2 \mathrm{DB}$ sites are also indicative of a seasonal effect related to low salinity. When tidal water sulfate concentrations are reduced by increased freshwater input, a major source of sulfate available to new growth in the spring may be newly oxidized sulfide. Iron sulfide minerals stored in marsh sediments begin to be chemically oxidized in winter (Kaplan et al. 1963). With active plant growth, chemical oxidation is supplemented by oxidation by roots of marsh plants (cf. Teal \& Kanwisher 1966, Howes et al. 1986, Ernst 1990). Spartina alterniflora has been shown to enhance the production of sulfate from iron sulfide minerals (Howarth \& Teal 1979). As there is little fractionation associated with sulfide oxidation (Toran \& Harris 1989), early spring sulfate derived from sulfide oxidation will be isotopically lighter than summer porewater sulfate derived from tidal water inputs.

\section{CONCLUSIONS}

In this study, $\delta^{34} \mathrm{~S}$ values of live Spartina alterniflora growing in poorly drained, organically rich sediments (HWY, DB2, BAY) were lighter than values for plants growing in irregularly flooded or sandier sites (DB1, $D Q$ ). It appears that the sulfur isotopic composition of $S$. alterniflora shoots depends strongly on the degree of accumulation of porewater sulfide, which is determined by hydrodynamic flushing and rates of sedimentary sulfate reduction.

For locations with similar sediment and hydrodynamic characteristics, salinity was negatively corre- lated with the $\delta^{34} \mathrm{~S}$ of Spartina alterniflora. Heavier isotopic values occurred at lower salinities. Sediments at those locations showed evidence of sulfate limitation, which would result in the production of an isotopically heavier porewater sulfide pool.

Seasonal variability was also found in the sulfur isotopic values of live Spartina alterniflora shoots between winter/spring and late summer. At higher salinity, $S$ alterniflora shoot $\delta^{34} \mathrm{~S}$ values decreased over the growing season, reflecting the accumulation of isotopically lighter sulfide. However, for plants growing at lower salinities, shoot $\delta^{34} \mathrm{~S}$ values remained steady or increased over the same period. Light early-season $\delta^{34} \mathrm{~S}$ values at these locations were linked to the reoxidation of sulfides in the absence of substantial tidal water sulfate. Heavier late-season values were associated with sulfate depletion and the resulting increase in the $\delta^{34} \mathrm{~S}$ of sulfide produced in the absence of replenishing tidal water sulfate.

This study has identified a number of factors that may be responsible for variability in sulfur stable isotopic composition of Spartina alterniflora. Further investigation is needed to establish the time required for the plant sulfur to respond to sediment sulfur variability, the importance of sequestering of sulfide (and sulfate) within plant tissues, and the relative importance of sulfate and sulfide in plant uptake, and to provide a detailed characterization of the stable isotopic composition of porewater sulfate and sulfide pools.

The $16.3 \%$ range in values of Spartina alterniflora $\delta^{34} \mathrm{~S}$ within the Monie Bay system exceeds the range of variability of $\delta^{34} \mathrm{~S}$ values reported for live shoots of this species in other study locations. Variability in isotopic signatures of $S$. alterniflora of almost this magnitude was also found in Massachusetts (Deegan \& Garritt 1997) among marshes with a very wide salinity range (0 to $30 \mathrm{ppt}$ ). Lower salinity systems certainly merit further study with respect to their diversity of chemical environments and the impact of their sulfur chemistry on the isotopic signature of primary producers.

Acknowledgements. Thanks to Bill Dennison. Todd Kana, Jeff Chanton, George Luther and 3 anonymous reviewers for critical input. We are also indebted to Michael Owens, Alison Sipler, Marilyn Mayer, Cathy Wigand, Lori Staver, Philippe Hensel, Karen Sundberg, and Jill Stevenson for field and laboratory assistance, and to Mary Noserino for access to the study site. This work was supported in part by the National Oceanic and Atmospheric Administration National Estuarine Research Reserve System, the National Science Foundation Land Margin Ecosystem Research Program (BSR-8814272), and the Coastal and Watershed Resources Division of the Maryland Department of Natural Resources 


\section{LITERATURE CITED}

Benner R, Fogel ML, Sprague EK (1991) Diagenesis of belowground biomass of Spartina alterniflora in salt-marsh sediments. Limnol Oceanogr 36:1358-1374

Carlson PR, Forrest J (1982) Uptake of dissolved sulfide by Spartina alterniflora: evidence from natural sulfur isotope abundance ratios. Science 216:633-635

Chambers LA, Trudinger PA (1979) Microbiological fractionation of stable sulfur isotopes: a review and critique Geomicrobiol J 1:249-293

Chukhrov FV, Ermilova LP, Churikov VS, Nosik LP (1980) The isotopic composition of plant sulfur. Org Geochem 2 $69-75$

Cline JD (1969) Spectrophotometric determination of hydrogen sulfide in natural waters. Limnol Oceanogr 14 $454-455$

Cornwell JC, Stevenson JC, Stribling JM (1990) Biogeochemical studies in the Monie Bay National Estuarine Research Reserve. Report No. NA89AA/D C2 130. Chesapeake Bay National Estuarine Research Reserve, Washington, DC

Currin CA, Newell SY, Paerl HW (1995) The role of standing dead Spartina alterniflora and benthic microalgae in salt marsh food webs: considerations based on multiple stable isotope analysis. Mar Ecol Prog Ser 121:99-116

Deegan LA, Garritt RH (1997) Evidence for spatial variability in estuarine food webs. Mar Ecol Prog Ser 147:31-47

Deegan LA, Peterson BJ, Porter R (1990) Stable isotopes and cellulase activity as evidence for detritus as a food source for juvenile gulf menhaden. Estuaries 13:14-19

Ernst WHO (1990) Ecophysiology of plants in waterlogged and flooded environments. Aquat Bot 38:73-90

Folk RL (1974) Petrology of sedimentary rocks. Hemphill Publishining Co, Austini, TX

Fry B, Scalan RS, Winters JK, Parker PL (1982) Sulphur uptake by salt grasses, mangroves, and seagrasses in anaerobic sediments. Geochim Cosmochim Acta 46: $1121-1124$

Fry B, Sherr EB (1984) $\delta^{13} \mathrm{C}$ measurements as indicators of carbon flow in marine and freshwater ecosystems. Contrib Mar Sci 27:13-47

Goering J, Alexander V, Haubenstock N (1990) Seasonal variability of stable carbon and nitrogen isotope ratios of organisms in a north Pacific bay. Estuar Coast Shelf Sci 30: $239-260$

Goldhaber MB, Kaplan IR (1980) Mechanisms of sulfur incorporation and isotope fractionation during early diagenesis in sediments of the Gulf of California. Mar Chem 9:95-143

Hall GEM, Pelchat JC, Loop J (1988) Separation and recovery of various sulphur species in sedimentary rocks for stable sulphur isotopic determination. Chem Geol 67:35-45

Hesslein RH (1976) An in situ sampler for close interval pore water studies. Limnol Oceanogr 21:912-914

Hines ME, Knollmeyer SL, Tugel JB (1989) Sulfate reduction and other sedimentary biogeochemistry in a northern New England salt marsh. Limnol Oceanogr 34:578-590

Howarth RW, Teal JM (1979) Sulfate reduction in a New England salt marsh. Limnol Oceanogr 24:999-1013

Howes BL, Dacey JWH, Goehringer DD (1986) Factors con-

Editorial responsibility: Gordon Thayer (Contributing Editor), Beaufort, North Carolina, USA trolling the growth form of Spartina alterniflora: feedbacks between above-ground production, sediment oxidation, nitrogen and salinity. J Ecol 74:881-898

Kaplan IR, Emery KO, Rittenberg SC (1963) The distribution and isotopic abundance of sulphur in recent marine sediments off southern California. Geochim Cosmochim Acta 27:297-331

Kearney MS, Stevenson JC, Ward LG (1994) Spatial and temporal changes in marsh vertical accretion rates at Monie Bay: implications for sea level rise. J Coastal Res 10: $1010-1020$

King GM (1988) Patterns of sulfate reduction and the sulfur cycle in a South Carolina salt marsh. Limnol Oceanogr 33: 376-390

Lambert CE, Oviatt CA (1986) Manual of biological and geochemical techniques in coastal areas. MERL Series, Report No. 1. University of Rhode Island, Kingston

Peterson BJ, Howarth RW (1987) Sulfur, carbon, and nitrogen isotopes used to trace organic matter flow in the saltmarsh estuaries of Sapelo Island, Georgia. Limnol Oceanogr 32:1195-1213

Peterson BJ, Howarth RW. Garritt RH (1985) Multiple stable isotopes used to trace the flow of organic matter in estuarine food webs. Science 227:1361-1363

Peterson BJ, Howarth RW, Garritt RH (1986) Sulfur and carbon isotopes as tracers of salt-marsh organic matter flow. Ecology 67:865-874

Simenstad CA, Duggins DO, Quay PD (1993) High turnover of inorganic carbon in kelp habitats as a cause of ${ }^{13} \mathrm{C}$ variability in marine food webs. Mar Biol 116:147-160

Stephenson RL, Tan FC, Mann KH (1984) Stable carbon isotope variability in marine macrophytes and its implications for food web studies. Mar Biol 81:223-230

Stribling JM (1994) Sulfur and nutrient chemistry of Spartina alterniflora in a low salinity marsh. $\mathrm{PhD}$ dissertation, University of Maryland

Stribling JM, Cornwell JC (1997) Identification of important primary producers in a Chesapeake Bay tidal creek system using stable isotopes of carbon and sulfur. Estuaries 20:77-85

Sullivan MJ, Moncreiff CA (1990) Edaphic algae are an important component of salt marsh food-webs: evidence from multiple stable isotope analyses. Mar Ecol Prog Ser 62:149-159

Teal JM, Kanwisher JW (1966) Gas transport in the marsh grass Spartina alterniflora. J Exp Bot 17:355-361.

Toran L, Harris RF (1989) Interpretation of sulfur and oxygen isotopes in biological and abiological sulfide oxidation. Geochim Cosmochim Acta 53:2341-2348

Trust BA, Fry B (1992) Stable sulphur isotopes in plants: a review. Plant Cell Environ 15:1105-1110

Wilkinson L (1990) SYSTAT the system for statistics. Systat, Inc, Evanston, IL

Zieman JC (1986) Variations of stable isotopic ratios in seagrasses in macrophyte based food webs as a function of source habitat. EOS 67:989

Zohary T, Erez J, Gophen M, Berman-Frank I, Stiller M (1994) Seasonality of stable carbon isotopes within the pelagic food web of Lake Kinneret. Limnol Oceanogr 39:1030-1043

Submitted: July 15, 1997; Accepted: March 19, 1998

Proofs received from author(s): May 11, 1998 